\title{
BMJ Open Development of a questionnaire to evaluate patients' awareness of cardiovascular disease risk in England's National Health Service Health Check preventive cardiovascular programme
}

\author{
Maria Woringer, ${ }^{1}$ Jessica Jones Nielsen, ${ }^{2}$ Lara Zibarras, ${ }^{2}$ Julie Evason, ${ }^{3}$ \\ Angelos P Kassianos, ${ }^{4}$ Matthew Harris, ${ }^{5}$ Azeem Majeed, ${ }^{1}$ Michael Soljak ${ }^{1}$
}

To cite: Woringer M, Nielsen JJ, Zibarras L, et al. Development of a questionnaire to evaluate patients' awareness of cardiovascular disease risk in England's National Health Service Health Check preventive cardiovascular programme. BMJ Open 2017;7:e014413. doi:10.1136/ bmjopen-2016-014413

- Prepublication history and additional material for this paper are available online. To view these files, please visit the journal online (http://dx.doi org/10.1136/bmjopen-2016014413).

Presented at the NHS Health Check 2015 - Improvement through Collaboration conference and the First International Conference of Public Health, Primary Care and Congress of Person Centred Medicine.

Received 22 September 2016 Revised 1 August 2017 Accepted 23 August 2017

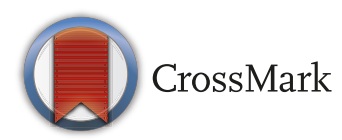

For numbered affiliations see end of article.

Correspondence to

Dr Maria Woringer;

m.woringer@imperial.ac.uk

\section{ABSTRACT}

Background The National Health Service (NHS) Health Check is a cardiovascular disease (CVD) risk assessment and management programme in England aiming to increase CVD risk awareness among people at increased risk of CVD. There is no tool to assess the effectiveness of the programme in communicating CVD risk to patients.

Aims The aim of this paper was to develop a questionnaire examining patients' CVD risk awareness for use in health service research evaluations of the NHS Health Check programme.

Methods We developed an 85-item questionnaire to determine patients' views of their risk of CVD. The questionnaire was based on a review of the relevant literature. After review by an expert panel and focus group discussion, 22 items were dropped and 2 new items were added. The resulting 65 -item questionnaire with satisfactory content validity (content validity indices $\geq 0.80$ ) and face validity was tested on 110 NHS Health Check attendees in primary care in a cross-sectional study between 21 May 2014 and 28 July 2014.

Results Following analyses of data, we reduced the questionnaire from 65 to 26 items. The 26 -item questionnaire constitutes four scales: Knowledge of CVD Risk and Prevention, Perceived Risk of Heart Attack/Stroke, Perceived Benefits and Intention to Change Behaviour and Healthy Eating Intentions. Perceived Risk (Cronbach's $\alpha=0.85$ ) and Perceived Benefits and Intention to Change Behaviour (Cronbach's $\alpha=0.82$ ) have satisfactory reliability (Cronbach's $\alpha \geq 0.70$ ). Healthy Eating Intentions (Cronbach's $\alpha=0.56$ ) is below minimum threshold for reliability but acceptable for a three-item scale.

Conclusions The resulting questionnaire, with satisfactory reliability and validity, may be used in assessing patients' awareness of CVD risk among NHS Health Check attendees.

\section{INTRODUCTION}

Cardiovascular disease (CVD) is a major cause of disability and premature mortality worldwide. In England, it accounts for a third of deaths and costs the National Health Service
Strengths and limitations of this study

- Questionnaire guided by literature review, expert panel, patient focus group and data analysis.

- Largely developed among 110 individuals representative of the target population.

- Face validity assessed via a patient focus group not representative of the target population.

(NHS) and the UK economy £30 billion annually. ${ }^{12}$ Modifiable lifestyle risk factors, associated with $90 \%$ of CVD,${ }^{34}$ contributed to only $34 \%$ of the overall decline in CVD mortality in England between 2000 and 2007..$^{5}$ In 2010/2011, there were 1.4 million CVD-related hospital admissions, of which $60 \%$ were for people younger than 75 and more than half as an emergency. Further gains could be made in preventing long-term illness and disability associated with CVD while reducing healthcare costs by promoting healthier lifestyle changes. ${ }^{6}$

The NHS Health Check programme may be important for preventing premature CVD while reducing healthcare costs therein by identifying individuals at increased risk of CVD, raising their awareness of CVD risk and helping them manage their risk. ${ }^{7-10}$ This CVD risk assessment and management programme was launched by the Department of Health in April 2009 in England among those aged 40-74years free of vascular disease diagnosis. ${ }^{7}$ It aims to prevent heart disease, stroke, diabetes and kidney disease while reducing health inequalities. Individuals' sociodemographics, cholesterol, blood pressure, smoking and family history of CVD are used to predict CVD risk. ${ }^{11}$ In addition to lifestyle advice given to all participants, people at high risk of CVD are invited for 


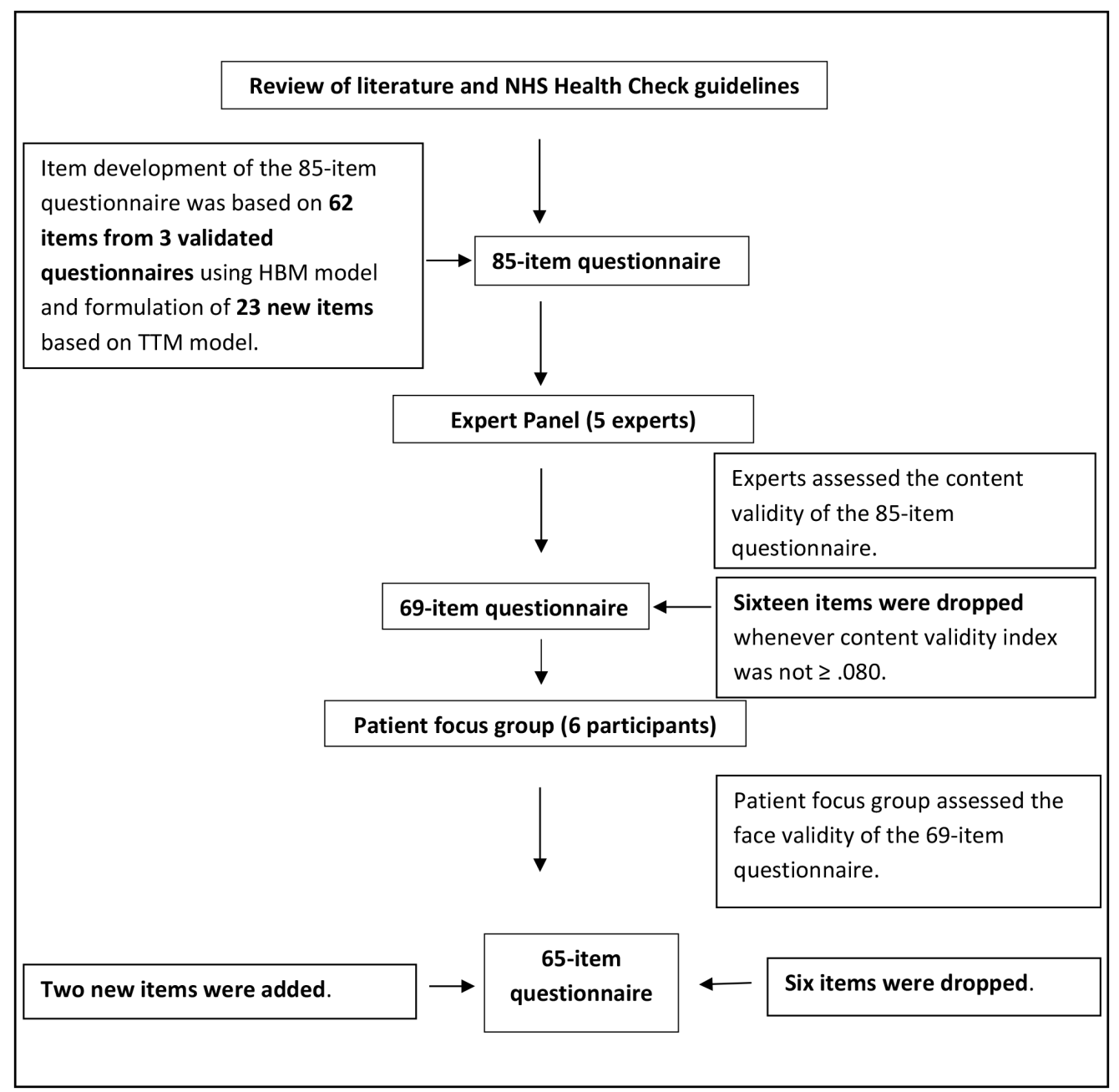

Figure 1 Flow chart of phase I of questionnaire development. HBM, Health Belief Model; NHS, National Health Service; TTM, Transtheoretical Model.

further consultations and offered statins and behaviour change support in relation to physical activity, smoking cessation, safe alcohol consumption and healthy diet. Projected programme cost is £180-£243million/year with estimated cost per quality adjusted life-year (QALY) at $£ 3000.1^{10}$

To adopt healthy lifestyle behaviours related to diet, exercise, smoking and alcohol consumption, the general population must be aware of CVD risk. ${ }^{12}$ In the context of the NHS Health Check Programme, CVD risk awareness refers to the accuracy of perceived risk of CVD against predicted CVD risk, general knowledge of CVD and what one can do to lower predicted CVD risk. Whereas predicted CVD risk refers to one's chance of experiencing a heart attack or stroke, ${ }^{11}$ perceived risk of CVD refers to a person's perception of their CVD risk. While as many as $40 \%$ of the general population underestimate their CVD risk, $20 \%$ overestimate their risk. ${ }^{13}$ False reassurance may lead to adoption and/or maintenance of unhealthy behaviours contributing to the premature onset of CVD. Low CVD risk awareness is reported among men, inner city residents and people of lower socioeconomic status. ${ }^{12} 1415$ It is not known if the Health Check results in improved CVD risk awareness.

Although several validated questionnaires measure knowledge, perceptions of CVD or intention to change behaviour, ${ }^{15-17}$ no short, validated questionnaire assesses CVD risk awareness using all of these scales. Until now studies examining the accuracy of perceived risk and knowledge of CVD relied on non-validated tools. ${ }^{16}$ The problem with using non-validated tools is that the questions may not accurately and reliably capture individuals' views or measure what they intend to measure. The aim of this work was to develop a questionnaire with satisfactory face, content validity and reliability to assess patients' awareness of CVD risk among NHS Health Check attendees.

\section{METHODS}

The first phase of development of the questionnaire was guided by a literature review, an expert panel and a patient focus group. At each stage of questionnaire development, the number of items was reduced (see figure 1). 


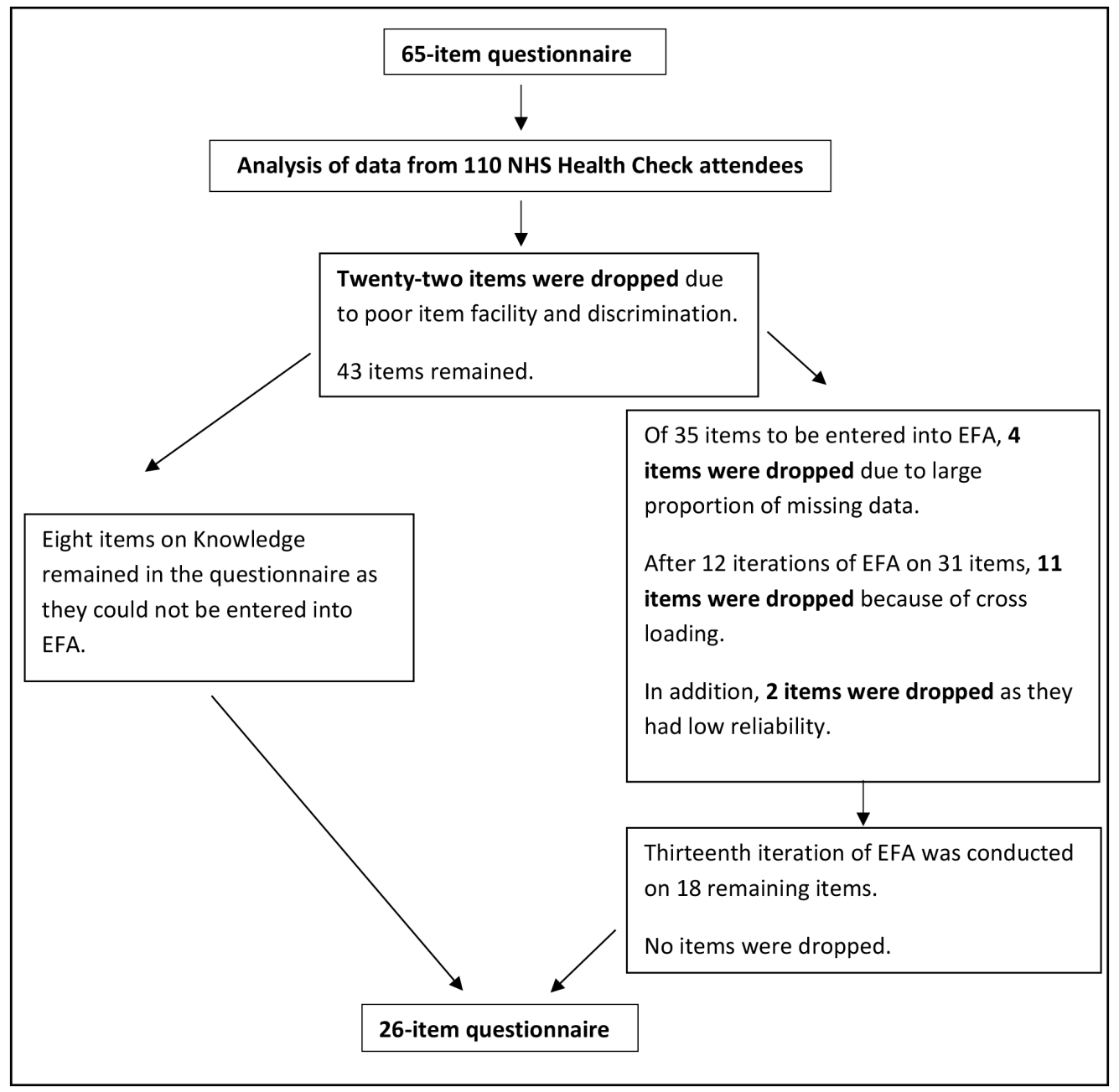

Figure 2 Flow chart of phase II of questionnaire development. EFA, exploratory factor analysis; NHS, National Health Service.

The second phase of questionnaire development was guided by an analysis of data from 110 NHS Health Check attendees who completed the 65 -item questionnaire. The number of questionnaire items was further reduced (see figure 2).

\section{Phase I of questionnaire development}

Construction of draft questionnaire by review of relevant literature We performed an extensive literature review pertaining to CVD risk awareness between December 2013 and January 2014 in the areas of disease knowledge, risk perception, intention to change and self-efficacy related to CVD and the Health Belief Model (HBM) to guide initial item development. PubMed and PsycINFO databases and Google Scholar Articles were used to search for existing instruments that measure perception of CVD risk, CVD knowledge and self-efficacy with no limits on the year of publication. The following keywords were used to identify the relevant literature: 'cardiovascular disease', 'heart disease', 'knowledge', 'risk', 'test', 'questionnaire', 'scale', 'assessment', 'self-efficacy', 'perception', 'health belief model'. Questionnaires were considered if they addressed CVD risk awareness, reported moderate-tohigh scores of reliability and validity in population studies and had suitable wording and level of understanding. Questionnaires were excluded if they pertained to individuals under the age of 15 as these people would not be eligible to receive an NHS Health Check, focused on risk unrelated to heart attack or stroke, and were not written in English.

Although a number of questionnaires were found measuring different aspects of CVD risk awareness such as heart disease knowledge, perception of CVD risk, perceived susceptibility and severity of CVD and benefits and barriers to adopting healthy behaviours, ${ }^{17-19}$ no single questionnaire encompassed them all. Initial item development was guided by $\mathrm{HBM}^{20}$ and the Transtheoretical Model (TTM) ${ }^{21}$ According to HBM, individuals who have accurate knowledge of CVD and perceived susceptibility to and consequences of the disease, and are aware of the benefits of taking preventive measures are more likely to make important lifestyle choices to prevent the onset of disease. ${ }^{22}$ The TTM describes behavioural change as a staged process over time including precontemplation, contemplation, preparation, action and maintenance. ${ }^{21}$ Sixty-five items were selected using validated questionnaires addressing CVD knowledge, 
and the main constructs of HBM such as perceived susceptibility, perceived severity, perceived benefits of changing behaviours and perceived barriers to making changes. ${ }^{17-19}$ In addition, 23 new items were generated to identify perceived levels of readiness to engage in CVD risk reduction behaviours (using TTM) and self-efficacy (confidence in ability to change health behaviour) in relation to exercise, diet, smoking cessation and decreasing alcohol consumption. ${ }^{23}{ }^{24}$ These items were based on data collected during an NHS Health Check and behaviour-specific recommendations such as stopping smoking, consuming no more than 14 units of alcohol a week, eating at least five portions of fruit and vegetables a day and exercising at least $150 \mathrm{~min}$ per week. ${ }^{25-28}$ The resulting 85-item questionnaire is presented in online supplementary appendix A.

\section{Modification of questionnaire by expert panel to obtain satisfactory} content validity

A panel of experts in the areas of CVD, health psychology, public health, psychometrics and questionnaire development and medicine were asked to evaluate each item and the total 85-item questionnaire for content validity in February 2014. Experts assessed content validity of the questionnaire by examining whether the items were representative of the content they were intended to measure. ${ }^{29}$ Items were examined for representatives of the scale domain, appropriateness and relevance. The content validity index (CVI), a widely used technique in scale development determined item and questionnaire clarity, homogeneity and relevance on a 4-point Likert scale (ranging from $1=$ anirrelevant item to $4=$ an extremely relevant item). ${ }^{30}{ }^{31}$ A CVI of $\geq 0.80$ is recommended. ${ }^{32} 33$ Experts were asked the following questions: 'Do these items belong together in the subscale?' and 'Does each item belong in the set?' For ratings of content validity, experts were asked whether the subscale definition and label fitted the set of items presented; whether each item belonged with the label and definition and whether each item was unique in its contribution to the subscale.

\section{Modification of questionnaire by patient focus group to obtain satisfactory face validity}

Researchers facilitated a patient focus group to assess the face validity of the 69-item questionnaire resulting from the expert review. Face validity is assessed by end users deciding whether the questionnaire appears to measure what the researchers who developed it claim. ${ }^{33}$ A convenience sample of six individuals was recruited on 2 March 2014 from the County Durham and Darlington NHS Foundation Trust. Eligibility criteria were being aged 40-74 years and being free of known vascular disease. The focus group consisted of six white females between 50 and 64 years of age. Most participants had postgraduate education. These individuals worked as clerical workers, nurses and health improvement staff. They were not involved in the delivery of the NHS Health Check programme. Participants were asked to complete the 69-item questionnaire as well as to provide feedback on whether the items correctly measured the intended scales, appropriately stated the intent of the questionnaire and matched the individual's situations. ${ }^{32}{ }^{33}$ In addition, participants were asked to respond to questions about clarity, content, appropriateness, format, biases of questions and presentation of information. The resulting 65 -item questionnaire is presented in online supplementary appendix B.

\section{Phase II of questionnaire development \\ Modification of questionnaire to have satisfactory reliability}

A 65-item questionnaire was administered to 110 NHS Health Check attendees immediately after their consultation between 21 May 2014 and 28 July 2014 in a cross sectional study in England. The aim was to determine the content, the scale structure and the reliability of the resulting questionnaire.

\section{Study recruitment}

Eligibility criteria were completion of an NHS Health Check, being aged 40-74 years and free of known vascular disease. Of 110 study participants, 15 individuals were recruited by 2 nurses from a London general practice and 95 individuals by 13 community outreach providers from local community venues in Durham. These providers collected clinical risk factor data, informed study participants about their CVD risk, took informed study consent and distributed the 65-item questionnaire to be self-completed by NHS Health Check attendees following their consultation. Unlike general practice staff who operated only during business hours, community outreach providers worked on evenings and weekends as well as during regular business hours in community venues more accessible to the general public.

\section{Data analysis}

To select appropriate items to constitute a scale, individual items were assessed during item analysis, item facility and item discrimination. ${ }^{34}$ To determine the factorial structure of the questionnaire and which items together constituted particular scales, an exploratory factor analysis (EFA) - a widely used technique in scale development was performed. ${ }^{3035}$ The reliability of factors constituting particular scales was assessed using Cronbach's $\alpha$ coefficient. ${ }^{36}{ }^{37}$ Reliability refers to consistency, reproducibility and agreement of a scale. ${ }^{38}$

To improve the quality of a scale and increase its reliability, individual items were assessed. Items with reverse scoring were recoded to conform to the conceptual direction of the scales. ${ }^{37}$ Each individual item was then examined for distortions in the pattern of responding known as skew and kurtosis. ${ }^{33}$ Item facility examined whether items were answered in the same way by everyone by checking whether the facility index approached extreme scores or had a low SD. ${ }^{34}$ Items were assessed in discriminating between participants' responses to the questionnaire's scales (Knowledge, Perceived CVD Risk, CVD Health 
Table 1 Sample item wording modifications obtained through an expert panel

\begin{tabular}{|c|c|c|}
\hline Original item(s) & Expert comments & Final item \\
\hline $\begin{array}{l}\text { The most important cause of heart attack } \\
\text { and stroke is stress. }\end{array}$ & $\begin{array}{l}\text { Revise to 'one of the most important...' } \\
\text { Substitute the word 'important' with } \\
\text { 'main'. }\end{array}$ & $\begin{array}{l}\text { One of the main causes of heart attack } \\
\text { and stroke is stress. }\end{array}$ \\
\hline $\begin{array}{l}\text { I have a high chance of getting a heart } \\
\text { attack or stroke because of my past } \\
\text { behaviours. }\end{array}$ & Add 'and/or present behaviours'. & $\begin{array}{l}\text { I have a high chance of getting a heart } \\
\text { attack or stroke because of my past and/ } \\
\text { or present behaviours. }\end{array}$ \\
\hline $\begin{array}{l}\text { Eating a healthy diet will decrease my } \\
\text { chance of having } \\
\text { a heart attack or stroke. }\end{array}$ & Define a healthy diet. & $\begin{array}{l}\text { Eating at least five portions of fruit and } \\
\text { vegetables a day will decrease my } \\
\text { chances of having a heart attack or } \\
\text { stroke. }\end{array}$ \\
\hline $\begin{array}{l}\text { How confident are you that you know } \\
\text { or can...? questions answered using a } \\
5 \text {-point Likert scale: } \\
\text { 'not at all confident, somewhat confident, } \\
\text { moderately confident, very confident, } \\
\text { completely confident'. }\end{array}$ & $\begin{array}{l}\text { Use a 4-point Likert to maintain } \\
\text { consistency. }\end{array}$ & $\begin{array}{l}\text { Five-point Likert scale changed to a } \\
\text { 4-point Likert scale: } \\
\text { 'not at all confident, somewhat confident, } \\
\text { very confident, completely confident'. }\end{array}$ \\
\hline $\begin{array}{l}\text { How confident are you that you know } \\
\text { how or can stop smoking if you want to? }\end{array}$ & $\begin{array}{l}\text { Instead of saying '....that you know or } \\
\text { can' say 'that you know how to or can...' } \\
\text { Add in parentheses 'if you smoke'. }\end{array}$ & $\begin{array}{l}\text { How confident are you that you know } \\
\text { how to or can stop smoking if you want } \\
\text { to (if you smoke)? }\end{array}$ \\
\hline $\begin{array}{l}\text { I want to cut down on alcohol. } \\
\text { I intend to cut down on alcohol in the } \\
\text { next } 2 \text { months. }\end{array}$ & $\begin{array}{l}\text { Conceptual overlap between want to and } \\
\text { intend to. } \\
\text { Add in parentheses 'if you drink alcohol'. }\end{array}$ & $\begin{array}{l}\text { I intend or want to cut down on alcohol (if } \\
\text { you drink alcohol). }\end{array}$ \\
\hline
\end{tabular}

Beliefs, Intentions/Readiness to Change and Self-Efficacy). Discrimination was measured by item-total correlation with item correlating below 0.2 or any negative correlations resulting in deletion of items. In addition, discrimination was measured by the interitem correlation within each scale resulting in deletion of items correlating with other items $\geq 0.60$. $^{1734}$

A Kaiser-Meyer-Olkin (KMO) measure of sampling adequacy and a Bartlett's test of sphericity were assessed to ensure that items were appropriate for EFA. ${ }^{39}$ Next, EFA was performed to define the scales of the questionnaire which share a similar underlying construct. Parallel analysis was used to determine the optimum number of factors to be extracted using principal components analysis (PCA) with a Varimax rotation. ${ }^{34} 3940$ PCA is a data reduction technique used to explain correlations among sets of items or variables as a few conceptually meaningful factors. ${ }^{30}$ Compared with other available methods, parallel analysis using PCA was shown to be the best method of extracting factors and is appropriate when applied to data conforming to the formal factor analytic model. ${ }^{3940}$ Iterations of EFA were carried out to identify core constituent items in each factor. Cross-loading items or items with loading $\leq 0.50$ were removed at each iteration. ${ }^{39}$ Internal consistency reliability of resulting factors was assessed using Cronbach's $\alpha$ coefficients with $\alpha \geq 0.70$ indicating good reliability. ${ }^{32} 3637$ Associations between resulting factors and predicted CVD risk were examined using Spearman's rank correlation coefficient.

\section{RESULTS}

Construction of a draft questionnaire by review of relevant literature

We developed an 85-item questionnaire based on the theoretical framework, NHS guidelines and other validated questionnaires relating to heart disease. ${ }^{17-19}$ The 85-item questionnaire had 8 subscales measuring Knowledge of CVD Risk and Prevention (18 items), Perceived Risk and Vulnerability of CVD (20 items), Perceived Susceptibility (5 items), Perceived Severity (5 items), Perceived Benefits (6 items), Perceived Barriers (7 items), Self-Efficacy (6 items) and Intention to Change Behaviour (18 items). Knowledge of CVD Risk and Prevention subscale items were measured using the following categories: true, false and do not know. Self-Efficacy subscale items were measured using 5-point Likert scale ranging from $1=$ not at all confident to 5=completelyconfident. Perceived Severity, Perceived Benefits, Perceived Barriers and Intention to Change Behaviour subscale items were measured using a 4-point Likert scale ranging from $1=$ strongly disagree to $4=$ strongly agree. The reading level of the questionnaire was at year 7 . 
Table 2 Sample item wording modifications and additions through the patient focus group

\begin{tabular}{|c|c|c|}
\hline Original item & Participant comments & Final item \\
\hline $\begin{array}{l}\text { Moderate physical activity of } 150 \text { min a week } \\
\text { will reduce your chances of developing a } \\
\text { heart or stroke. }\end{array}$ & $\begin{array}{l}2.5 \text { hours a week is better than } \\
150 \text { min. }\end{array}$ & $\begin{array}{l}\text { Moderate physical activity of } 2.5 \text { hours a week } \\
\text { will reduce your chances of developing a } \\
\text { heart or stroke. }\end{array}$ \\
\hline $\begin{array}{l}\text { Drinking alcohol has nothing to do with } \\
\text { reducing the risk of heart attack or stroke. }\end{array}$ & Question is negatively stated. & $\begin{array}{l}\text { Drinking high levels of alcohol can increase } \\
\text { your cholesterol and triglyceride levels. }\end{array}$ \\
\hline Missing question & $\begin{array}{l}\text { Need to include family history of } \\
\text { disease to account for genetic } \\
\text { predisposition. }\end{array}$ & $\begin{array}{l}\text { A family history of hypertension is not a risk } \\
\text { factor for high blood pressure. }\end{array}$ \\
\hline Missing question & Benefits of not smoking? & $\begin{array}{l}\text { If I stopped smoking it will reduce my chances } \\
\text { of having a heart attack or stroke. }\end{array}$ \\
\hline $\begin{array}{l}\text { Increasing my exercise for } 30 \text { min a day will } \\
\text { decrease my chances of having a heart attack } \\
\text { or stroke. }\end{array}$ & $\begin{array}{l}\text { Two and a half hours a week is } \\
\text { better than } 30 \text { min a day. }\end{array}$ & $\begin{array}{l}\text { Increasing my exercise to at least } 21 / 2 \text { hours } \\
\text { a week will decrease my chances of having a } \\
\text { heart attack or stroke. }\end{array}$ \\
\hline $\begin{array}{l}\text { How confident are you that you know how } \\
\text { to or can consume recommended levels of } \\
\text { alcohol (if you drink alcohol)? } \\
\text { 'not at all confident, somewhat confident, very } \\
\text { confident and completely confident'. }\end{array}$ & $\begin{array}{l}\text { Remove (if you drink alcohol). } \\
\text { Add a 'not applicable' box. }\end{array}$ & $\begin{array}{l}\text { How confident are you that you know how to } \\
\text { or can drink within the recommended levels of } \\
\text { alcohol? } \\
\text { 'not at all confident, somewhat confident, } \\
\text { very confident and completely confident, not } \\
\text { applicable'. }\end{array}$ \\
\hline
\end{tabular}

\section{Modification of questionnaire by expert panel to obtain satisfactory content validity}

The expert panel concluded that out of the 85 items, 69 met the CVI $\geq 0.80$ criterion and were retained. In addition, the wording of a number of questions was revised to improve clarity. Diet and exercise were defined more precisely using frequency and duration. Response options of Self-Efficacy items were changed from a 5-point Likert scale to a 4-point Likert scale for consistency with the rest of the questionnaire. Questions pertaining to smoking and drinking were rephrased to apply to smokers and drinkers (see table 1).

\section{Modification of questionnaire by patient focus group to obtain satisfactory face validity}

As a result of the focus group review of the 69-item questionnaire, 6 items were removed, 2 items were added and a number of items were modified leaving a final total of 65 items with satisfactory face validity. A not applicable category was added to 50 items while the response categories to Knowledge subscale items remained unchanged. Exercise was redefined in 8 items from 150 min a week and $30 \mathrm{~min}$ a day to 2.5 hours a week. A negatively framed question was reframed positively (see table 2).

\section{Modification of questionnaire to have satisfactory reliability}

The 65-item questionnaire that resulted from content and face validity assessments, was administered to 110 NHS Health Check attendees immediately after their NHS Health Check consultation. Most study participants were white $(84.5 \%)$, younger than $60(77.3 \%)$ and had at least one or more CVD risk factors. Using the Index of Multiple Deprivation, a relative measure of deprivation across seven distinct domains including income, employment, health and disability, education skills and training, barriers to housing and services, living environment and crime, ${ }^{41}$ people in the two most deprived fifths were $40.9 \%$ of the study population (see online supplementary appendix C) for study population characteristics. The responses to the questionnaire were analysed as individual items during item analysis, item facility and item discrimination. In addition, the scale structure and reliability of resulting scales were assessed.

No items were removed during item analysis and item facility. During item discrimination assessment using itemtotal correlation, seven items in the Knowledge scale, four items in Perceived CVD Risk, three items in CVD Health Benefits, three items in Intention and or Readiness to Change were deleted due to item-total correlations falling below $0.2 .{ }^{33}$ During item discrimination assessment using interitem correlation, two items in Perceived CVD Risk and three items in Intentions/Readiness to Change were removed as these items correlated $>0.6$ with other items. ${ }^{33}$ Although there were two items that correlated above 0.6 in CVD Risk Reduction Self-Efficacy, these remained in the questionnaire as the items were qualitatively different: Stop smoking if you want to and Control the risks of having a heart attack or stroke. In total, 22 items were removed during item discrimination analysis, leaving 43 items which had good item facility and discrimination. 
It is likely that I will suffer from a heart attack or stroke in the future.

It is likely that I will have a heart attack or stroke some time during my life.

\section{Components}

Factor 1

Perceived risk of heart attack/ stroke

\begin{tabular}{ll}
$\begin{array}{l}\text { Factor } 2 \\
\text { Perceived benefits and } \\
\text { intentions to change }\end{array}$ & $\begin{array}{l}\text { Factor } 3 \\
\text { intentions eating }\end{array}$ \\
\hline
\end{tabular}

0.844

0.816

I feel I will suffer from a heart attack or stroke sometime during 0.809 my life.

There is a good chance I will experience a heart attack or $\quad 0.752$ stroke in the next 10years.

$\begin{array}{ll}\text { I am not worried that I might have a heart attack or stroke. } & 0.705 \\ \text { My chances of suffering from a heart attack or stroke in the } & 0.687\end{array}$
next 10 years are great.

It is likely I will have a heart attack or stroke because of my $\quad 0.639$ past and/or present behaviours.

I am concerned about the likelihood of having a heart attack or 0.575

stroke in the near future.

I am thinking about exercising at least $2 \frac{1}{2}$ hours a week. 0.826

I intend or want to exercise at least $21 / 2$ hours a week. 0.792

When I exercise for at least $2 \frac{1}{2}$ hours a week I am doing 0.735 something good for the health of my heart.

I am confident that I can maintain a healthy weight by exercising at least $2 \frac{1}{2}$ hours a week within the next 2 months.

$\begin{array}{ll}\text { I am not thinking about exercising for } 2 \frac{1}{2} \text { hours a week. } & 0.656 \\ \text { When I eat at least five portions of fruit and vegetables a day I } & 0.642\end{array}$
am doing something good for the health of my heart.

$\begin{array}{ll}\text { Increasing my exercise to at least 21/2 hours a week will } & 0.557\end{array}$
decrease my chances of having a heart attack or stroke. I am confident that I can eat at least five portions of fruit and vegetables per day within the next 2 months.

I am thinking about eating at least five portions of fruit and
vegetables a day.
I am not thinking about eating at least five portions of fruit and
vegetables a day.

Factor loadings and commonalities are reported following an EFA using principal component analysis with Varimax rotation.

Of the 43 remaining items, 8 items of the 'Knowledge' scale with 'true' or 'false'scoring could not be entered into EFA. Of the 35 items scored on a 4-point Likert scale, four items pertaining to smoking were deleted as they had a high proportion of missing responses $(69 \%-80 \%)$. The resulting 31 items had a KMO measure of sampling adequacy of 0.32 and a significant Bartlett's test of sphericity $(1020.50, \mathrm{p}<0.001)$, indicating that these data were appropriate for EFA. ${ }^{39}$ After 12 iterations of EFA, 20 items loaded above 0.50 on the factors and there were no cross-loadings indicating good factor structure (see table 3). Internal consistency reliability of factor structure was measured using Cronbach's $\alpha$. Factor 1 (eight items): (Perceived Risk of Heart Attack/Stroke) had $\alpha=0.85$.
Factor 2 (seven items): (Perceived Benefits and Intentions to Change) had $\alpha=0.82$. Factor 3 (three items): (Healthy Eating Intentions) had $\alpha=0.56$. Factor 4 (two items): (Intentions towards Alcohol) had $\alpha=-0.16$. Although Healthy Eating Intentions $\alpha=0.56$ is below the minimum threshold (0.70) for reliability, this is acceptable for a three-item scale. ${ }^{34}$ The intention towards alcohol factor had two items with such low reliability $(\alpha=-0.16)$ that they could not be considered a separate factor and were removed. A 13th EFA iteration confirmed the factor loadings and reliabilities reported above. Hence, the parallel analysis indicated that three factors should be retained. ${ }^{39}$ The three-factor model accounted for $57.61 \%$ of the total explained variance. 
The EFA revealed three scales: Perceived Risk of Heart Attack/Stroke, Perceived Benefits and Intentions to Change and Healthy Eating Intentions. A fourth scale assessing Knowledge of CVD Risk and Prevention (not entered into EFA) was added back to the questionnaire following EFA (see figure 2). Hence, the resulting questionnaire included 26 items grouped into four scales: Knowledge of CVD Risk and Prevention (eight items), Perceived Risk of Heart Attack/Stroke (seven items), Perceived Benefits and Intention to Change Behaviour (seven items) and Healthy Eating Intentions (three items). In the resulting 26-item questionnaire, two items were changed from questions "How confident are you that you know how to or can..." to statements of agreement "I am confident that I can" so as to be answered using the same Likert scale. The time to complete this questionnaire is between 10 and $15 \mathrm{~min}$. The ABCD Risk Questionnaire with a scoring guide for each scale is reported in online supplementary appendix D. Using Spearman's rho, there was a positive and significant relationship between perceived and predicted CVD risk (see online supplementary appendix E).

\section{DISCUSSION}

To the best of our knowledge, this is the first study that describes the development of a short, validated questionnaire with satisfactory content and face validity and reliability examining CVD risk awareness among the NHS Health Check attendees. The ABCD Risk Questionnaire may be used for evaluating the accuracy of perceived CVD risk, general knowledge of CVD and intention to change behaviour in regard to diet and exercise among NHS Health Check attendees. Agreement between perceived and predicted CVD risk suggests that the tool performs well in assessing perceived CVD risk. As the questionnaire was developed using both an expert panel and a patient focus group, it ought to be relatively easy to understand for both patients and clinicians. If NHS Health Check recommendations change over time, it may need to be updated.

Critics of the NHS Health Check programme point to the lack of its evidence base. ${ }^{42} 43$ The majority of evaluations focused on coverage and uptake, statin prescribing, new diagnoses and CVD risk factor reduction. ${ }^{44-49}$ As there was no instrument measuring CVD risk awareness, no studies examined the patients' understanding of CVD risk among NHS Health Check attendees. CVD risk presentation was shown to increase the accuracy of perceived risk by $10 \%$. When risk information is repeated, this leads to small but significant reductions in predicted CVD risk. ${ }^{16}$ A national study showed modest reductions in 10-year predicted CVD risk among NHS Health Check attendees in the first 4 years. ${ }^{48}$ A limitation of using predicted 10-year risk of CVD is the underestimation of CVD risk among women and younger people. ${ }^{35}$ More research is needed to establish whether the programme improves NHS Health Check attendees' awareness of
CVD risk and whether the programme has an impact on predicted lifetime CVD risk.

The ABCD Risk Questionnaire was developed on a non-risk stratified population after their initial NHS Health Check consultation as the NHS Health Check programme is administered to all eligible people free of vascular disease diagnosis irrespective of their level of CVD risk. The questionnaire does not encompass all aspects of CVD risk observed in the general population. Questions on smoking and drinking were progressively eliminated as they did not apply to most study participants. As questions on diet and exercise pertained to all people regardless of their level of CVD risk, such questions that reliably distinguished between study participants were selected for inclusion. Although fruit and vegetable intake is only one aspect of diet in the EatWell Guide recommended for use in NHS Health Check, ${ }^{50}$ it is the only assessment of diet recorded during the NHS Health Check. The resulting questionnaire contains questions based on data collected during NHS Health Check to enable subsequent programme evaluation. ${ }^{51}$ Future studies examining populations at increased CVD risk can look into incorporating smoking and alcohol into the ABCD Risk Questionnaire to learn about these individuals' preconceptions and attendance of follow-up care.

Judging by the number of items reduced in various stages of development, the ABCD Risk Questionnaire was largely shaped by analysis of data from 110 NHS Health Check attendees completing the 65-item questionnaire. This study population was representative of the population that took up the NHS Health Check programme between 2009 and 2014 in terms of sociodemographics including the proportion of men $(46.4 \%)$, ethnic minorities $(5.4 \%)$, individuals from the most deprived two-fifths $(40.9 \%)$, and clinical risk factors including mean total cholesterol (5.42 (95\% CI 5.19 to 5.64)), body mass index (27.24 95\% CI 26.17 to 28.31 ), smokers $(18.2 \%)$ and those at high CVD risk (4.5\%). ${ }^{44}$ As higher levels of deprivation are partly due to having less education, ${ }^{41}$ questionnaire development was not limited to people with higher education. Compared with the national evaluation, similar levels of high CVD risk were observed despite the fact that the study population contained more younger people aged $40-59$ years $(77.3 \%) .{ }^{44}$ The recruitment of hard-to-reach groups including younger people, socioeconomically deprived individuals and ethnic minorities by community outreach providers in community venues outside of conventional working hours is consistent with prior literature. ${ }^{22} 52-54$

A possible limitation to face validity is that the patient focus group evaluating the 69-item questionnaire was not representative of the target population. Whereas the NHS Health Check programme is administered to both men and women and members of ethnic minorities, the focus group consisted only of white women. Furthermore, as these women had postgraduate education and worked in a health-related field, they may have had higher health literacy than the general population eligible for the NHS 
Health Check programme. Clarity, appropriateness, biases and presentation of information may have been differentially assessed by people with different levels of health literacy. A community-based recruitment method aiming to recruit some of the hard-to-reach groups may have been more effective in getting a more representative patient focus group.

Additional studies should be conducted with larger samples to confirm the reliability and validity of the questionnaire. It would be useful to replicate the factor analytic process on an independent, larger sample to confirm the generalisability of these findings. ${ }^{37}$

\section{CONCLUSIONS}

The ABCD Risk Questionnaire showed evidence of satisfactory reliability and validity, is brief and easy to use. By capturing patients' views on CVD risk awareness during an NHS Health Check consultation, the questionnaire can be used to assess patients' understanding of CVD risk. Clinicians administering the questionnaire to patients may help to establish whether the programme is effective in empowering patients to make informed lifestyle choices about their health.

\section{Author affiliations \\ ${ }^{1}$ Department of Primary Care and Public Health, Imperial College London, London, UK \\ ${ }^{2}$ Department of Psychology, City University London, London, UK \\ ${ }^{3}$ Health Diagnostics Ltd, Chester, UK \\ ${ }^{4}$ Department of Applied Health Research, University College London, London, UK \\ ${ }^{5}$ Institute of Global Health Innovation, Imperial College London, London, UK}

Contributors MW, AM, MS and HW designed the study, JE supplied the data. JJN designed the validation instrument, LZ performed the psychometric analysis. JE, AK, MH and AM reviewed the validation instrument's face and content validity. All authors discussed data analyses and interpreted the results. MW wrote the first draft of the manuscript. All authors critically revised and approved the final manuscript. MW had full access to all the data used in the study and takes responsibility for the integrity of the data and the accuracy of the data analysis. MW is the guarantor.

Funding This work was supported by the National Institute for Health Research (NIHR) Diagnostics Evidence Co-operatives (DEC)/Collaboration for Leadership in Applied Health Research and Care (CLAHRC) grant.

Competing interests None declared.

Ethics approval NRES Committee London-City and East.

Provenance and peer review Not commissioned; externally peer reviewed. Data sharing statement № additional data available.

Open Access This is an Open Access article distributed in accordance with the terms of the Creative Commons Attribution (CC BY 4.0) license, which permits others to distribute, remix, adapt and build upon this work, for commercial use, provided the original work is properly cited. See: http://creativecommons.org/ licenses/by/4.0/

(C) Article author(s) (or their employer(s) unless otherwise stated in the text of the article) 2017. All rights reserved. No commercial use is permitted unless otherwise expressly granted.

\section{REFERENCES}

1. World Health Organisation. Prevention of Cardiovascular Disease Guidelines for assessment and management of cardiovascular risk.
2007 http://www.who.int/cardiovascular_diseases/guidelines/Full\% 20text.pdf (accessed 08 Mar 2015).

2. Murray CJ, Richards MA, Newton JN, et al. UK health performance: findings of the Global Burden of Disease Study 2010. Lancet 2013;381:997-1020.

3. Barton GR, Goodall M, Bower P, et al. Increasing heart-health lifestyles in deprived communities: economic evaluation of lay health trainers. J Eval Clin Pract 2012;18:835-40.

4. Yusuf S, Hawken S, Ounpuu S, et al. Effect of potentially modifiable risk factors associated with myocardial infarction in 52 countries (the INTERHEART study): case-control study. Lancet 2004;364:937-52.

5. Bajekal M, Scholes S, Love H, et al. Analysing recent socioeconomic trends in coronary heart disease mortality in England, 2000-2007: a population modelling study. PLoS Med 2012;9:e1001237.

6. The National Institute for Health and Care Excellence (NICE). Services for the prevention of cardiovascular disease - NICE commissioning guides [CMG45]. 2012 https://www.nice.org. uk/guidance/cmg45/chapter/commissioning-services-for-theprevention-of-cardiovascular-disease (accessed 12 June 2015).

7. Department of Health. Putting prevention first- vascular checks: risk assessment and management - next steps guidance for primary care trusts,. 2009 http://www.dh.gov.uk/en/Publicationsandstatistics/Pub lications/PublicationsPolicyAndGuidance/DH_090277 (accessed 7 July 2016).

8. Public Health England. NHS Health Check Best Practice Guidance. 2015 http://www.healthcheck.nhs.uk/commissioners_and healthcare professionals/national guidance/ (accessed 6 Mar 2015).

9. Public Health England. NHS Health Check: Our Approach to the Evidence. 2013 https://www.gov.uk/government/uploads/system/ uploads/attachment_data/file/224537/NHS_Health_Check_our_ approach_to_the_evidence_v2.pdf; (accessed 12 Jun 2015).

10. Department of Health. Vascular Checks: Economic Modelling for Vascular Checks. 2008 http://www.dh.gov.uk/en/Publicationsandsta tistics/Publications/PublicationsPolicyAndGuidance/DH_085869 (accessed 12 Jun 2015).

11. Collins GS, Altman DG. Predicting the 10 year risk of cardiovascular disease in the United Kingdom: independent and external validation of an updated version of QRISK2. BMJ 2012;344:e4181.

12. Homko CJ, Santamore WP, Zamora L, et al. Cardiovascular disease knowledge and risk perception among underserved individuals at increased risk of cardiovascular disease. $J$ Cardiovasc Nurs 2008;23:332-7.

13. Webster R, Heeley E. Perceptions of risk: understanding cardiovascular disease. Risk Manag Healthc Policy 2010;3:49-60.

14. Kirkland SA, MacLean DR, Langille DB, et al. Knowledge and awareness of risk factors for cardiovascular disease among Canadians 55 to 74 years of age: results from the Canadian Heart Health Surveys, 1986-1992. CMAJ 1999;161:S10-16.

15. Potvin L, Richard L, Edwards AC. Knowledge of cardiovascular disease risk factors among the Canadian population: relationships with indicators of socioeconomic status. CMAJ 2000;162:S5-11.

16. Sheridan SL, Viera AJ, Krantz MJ, et al. The effect of giving global coronary risk information to adults: a systematic review. Arch Intern Med 2010;170:230-9.

17. Bergman HE, Reeve BB, Moser RP, et al. Development of a Comprehensive Heart Disease Knowledge Questionnaire. Am J Health Educ 2011;42:74-87.

18. Ammouri AA, Neuberger G. The Perception of Risk of Heart Disease Scale: development and psychometric analysis. J Nurs Meas 2008;16:83-97.

19. Tovar EG, Rayens MK, Clark M, et al. Development and psychometric testing of the Health Beliefs Related to Cardiovascular Disease Scale: preliminary findings. J Adv Nurs 2010;66:2772-84.

20. Strecher VJR. I.M. The Health Belief Model. In: Glanz K, Lewis FM, Rimer BK, Health Behavior and Health Education, Theory, Research and Practice. San Francisco: Jossey-Bass, 1997.

21. Prochaska JO, Redding CA, Evers KE. The Transtheoretical Model and Stages of Change. In: Glanz K, Lewis FM, Rimer BK, Health Behavior Education Health, Theory, Research and Practice. San Francisco: Jossey-Bass, 1997.

22. Hsu HY, Gallinagh R. The relationships between health beliefs and utilization of free health examinations in older people living in a community setting in Taiwan. J Adv Nurs 2001;35:864-73.

23. Prochaska JO, DiClemente CC, Norcross JC. In search of how people change. Applications to addictive behaviors. Am Psychol 1992;47:1102-14.

24. Prochaska JO, Norcross JC, DiClemente CC. Changing for Good: A Revolutionary Six-Stage Program for Overcoming Bad Habits and Moving Your Life Positively Forward. New York: NY Avon Books, 1994. 
25. Department of Health. Physical Activity Guidelines for Adults (19-64 Years). 2011 http://www.nhs.uk/Livewell/fitness/Documents/adults19-64-years.pdf (accessed 23 Apr 2015).

26. Department of Health. Improve Your NHS Health Check Numbers. 2014 http://www.nhs.uk/Conditions/nhs-health-check/Pages/Takeaction-to-improve-your-health.aspx (accessed 23 Apr 2015).

27. Department of Health. Five a Day. 2013 http://www.nhs.uk/livewell/ 5aday/Pages/ADAYhome.aspx (accessed 23 Apr 2015).

28. Health DO. Putting prevention first. Vascular risk assessment and management - best practice guidance.NHS health check, 2009.

29. Andrew S, Halcomb EJ. Mixed Methods Research for Nursing and the Health Sciences: Blackwell Publishing Ltd, 2009.

30. Chan CW. Perceptions of coronary heart disease: the development and psychometric testing of a measurement scale. Psychol Health Med 2014;19:159-68.

31. Wells KJ, Arevalo M, Meade CD, et al. Development and validation of the biobanking attitudes and knowledge survey (BANKS). Cancer Epidemiol Biomarkers Prev 2014;23:374-82.

32. Waltz CF, Strickland OL, Lenz ER. Measurement in Nursing Research. Second Edition. Philadelphia: FA Davis Company, 1991.

33. Waltz CF, Strickland OL, Lenz ER. Measurement in Nursing and Health Research. Fourth Edition. New York: edSpringer Publishing Company, 2010.

34. Rust J, Golombok S. Modern psychometrics: The science of psychological assessment. Second Edition. London: Routledge 1999.

35. JBS 3 Joint British Societies for the prevention of cardiovascular disease.Lifetime risk. 2014 http://www.jbs3risk.com/pages/lifetime_ risk.htm (accessed 9 Aug 2016).

36. Nunnally JC, Bernstein IH. Psychometric theory. Third Edition. New York: McGraw-Hill Higher, INC, 1994.

37. DeVellis RF. Scale Development Theory and Applications. Third Edition. Los Angelos / London / New Delhi / Singapore / Washington DC: SAGE, 2012

38. Aldridge V, Wade A, Koutoumanou E. Validity and Reliability University College London, Institute of Child Health2015.

39. Ferguson E, Cox T. Exploratory Factor Analysis: A Users? Guide. International Journal of Selection and Assessment 1993;1:84-94.

40. Zwick WR, Velicer WF. Comparison of five rules for determining the number of components to retain. Psychol Bull 1986;99:432-42.

41. Department for Communities and Local Government. The English Indices of Deprivation 2010 - Neighborhoods Statistical Release,
2011. https://www.gov.uk/government/uploads/system/uploads/ attachment_data/file/6871/1871208.pdf (accessed 16 Dec 2014).

42. Krogsbøll Lasse T, Jørgensen Karsten J. Grønhøj Larsen C and Gøtzsche Peter C. General health checks in adults for reducing morbidity and mortality from disease. Cochr Database of Syst Rev 2012.

43. Capewell S, Graham H. Will cardiovascular disease prevention widen health inequalities? PLoS Med 2010;7:e1000320.

44. Chang KC, Soljak M, Lee JT, et al. Coverage of a national cardiovascular risk assessment and management programme (NHS Health Check): Retrospective database study. Prev Med 2015;78:1-8.

45. Artac M, Dalton AR, Majeed A, et al. Effectiveness of a national cardiovascular disease risk assessment program (NHS Health Check): results after one year. Prev Med 2013;57:129-34.

46. Artac M, Dalton AR, Majeed A, et al. Uptake of the NHS Health Check programme in an urban setting. Fam Pract 2013;30:426-35.

47. Dalton AR, Bottle A, Okoro C, et al. Uptake of the NHS Health Checks programme in a deprived, culturally diverse setting: crosssectional study. J Public Health 2011;33:422-9.

48. Chang KC, Lee JT, Vamos EP, et al. Impact of the National Health Service Health Check on cardiovascular disease risk: a difference-indifferences matching analysis. CMAJ 2016;188:E228-E238.

49. Robson J, Dostal I, Sheikh A, et al. The NHS Health Check in England: an evaluation of the first 4 years. BMJ Open 2016;6:e008840.

50. Choices NHS. Eating a Balanced Diet.. 2016 http://www.nhs.uk/ Livewell/Goodfood/Pages/Healthyeating.aspx (accessed 27 April 2017).

51. Public Health England.. NHS Health Check Best practice guidance.. 2017 http://www.healthcheck.nhs.uk/commissioners and_providers/guidance/national_guidance1/ (accessed 27 April 2017).

52. Grayland J, Wilson R. Improving male life expectancy in Birmingham Public Health 2009;123:e50-e56.

53. Hunt BD, Hiles SL, Chauhan A, et al. Evaluation of the Healthy LifeCheck programme: a vascular risk assessment service for community pharmacies in Leicester city, UK. J Public Health 2013;35:440-6.

54. Visram S, Carr SM, Geddes L. Can lay health trainers increase uptake of NHS Health Checks in hard-to-reach populations? A mixed-method pilot evaluation. J Public Health 2015;37. 